Ann. Zootech., I975, 24 (I), I29-I32.

NOTE

\title{
TENEUR EN SÉLÉNIUM DU LAIT DE VACHE DANS LE NORD ONTARIEN
}

\author{
M. HIDIROGLOU et D. J. JENKINS \\ Ministère de l'A griculture, \\ Institut de Recherches zootechniques, \\ Animal Research Institute*, \\ Ottawa, Ontario (Canada) \\ KIA OCG
}

RÉSUMÉ

Une étude a été entreprise sur les teneurs en sélénium des laits des vaches Shorthorn du Nord Ontarien, où sévit à l'état endémique la myopathie du Veau. L'analyse de ces laits, échantillonnés à différents stades de lactation, a démontré la répercussion directe des rations alimentaires hivernales carencées en sélénium sur leurs teneurs en cet oligo-élément. En effet, la teneur en sélénium a varié de 8,6-II,4 ng/g de colostrum, et de I,5-2,4 $\mathrm{ng} / \mathrm{g}$ de lait. Lors de la mise au pâturage, on n'a remarqué aucun changement significatif dans les teneurs en sélénium des laits susceptible d'influencer l'apparition de la myopathie du Veau.

Le lait est l'unique source de sélénium pour les veaux de boucherie du Nord Ontarien où sévit la myopathie du Veau à l'état endémique. Des données sur la teneur en sélénium de ces laits sont donc nécessaires en vue d'évaluer si leur concentration est adéquate en cet élément pour la nutrition du Veau. Peu de résultats ont été publiés sur la teneur en sélénium du lait entier et frais des vaches de ces régions, où les animaux sont alimentés uniquement pendant I'hiver et en étable avec des fourrages pauvres en sélénium. L'apparition de la myopathie, quelques jours après la mise au pâturage des vaches et de leurs veaux (HIDIRoGLov et al., I967) nous a incité à étudier les modifications survenant dans la teneur en sélénium du lait des vaches quand ces dernières sont mises au pâturage.

* Contribution no 542 : Animal Research Institute. 


\section{MATÉRIEL, ET MÉTHODES}

En octobre 1970 quatre-vingts vaches gestantes Shorthorn de la ferme expérimentale de Kapuskasing, dans le Nord Ontarien, ont été réparties en quatre groupes de vingt et nourries de la façon suivante :
Groupe I : Ensilage de fourrage de tournesol ;
Groupe II : Ensilage de fourrage de colza ;
Groupe III : Ensilage de graminées et de légumineuses ;
Groupe IV : Foin.

Tous les animaux ont hiverné dans des étables et des sels minéraux composés en partie de sel de cuisine et de poudre d'os ont été mis à leur disposition.

Les vêlages ont eu lieu aux mois d'avril et mai et les animaux ont été mis au pâturage au I er juin $197 \mathrm{I}$. Le lait a été échantillonné immédiatement après le vêlage aux deuxième et quinzième jours suivants, puis $24 \mathrm{~h}$ avant et après la mise à l'herbe des animaux. Par la suite, l'échantillonnage du lait a eu lieu toutes les semaines pendant 8 semaines. Des échantillons de la ration hivernale et de la ration pastorale ont également été analysés périodiquement pour évaluer leur teneur en sélénium d'après la méthode de Hoffman et al. (r968). La traite a eu lieu le matin du jour d'échantillonnage et le lait a été analysé pour sa teneur en sélénium d'après la méthode précitée.

\section{RÉSULTATS E'T DISCUSSION}

Les valeurs obtenues sur les teneurs en sélénium des fourrages et du lait sont résumés dans les tableaux $\mathbf{I}$ et 2 . Comme il a déjà été rapporté pour d'autres fourrages d'herbe produits dans le Nord Ontarien (LESSARD et al. 1968), les ensilages de tournesol et de colza ainsi que ceux des autres fourrages se sont révélés pauvres en sélénium. Leurs concentrations en sélénium étaient en effet inférieures à Ioo nanogrammes par $g$, ce qui est considéré comme la quantité minimum permettant d'éviter la myopathie. Cette carence en sélénium des fourrages s'est reflétée sur la

TABLEAU I

Teneurs en sélénium $(\mathrm{ng} / \mathrm{g})$ de la ration

\begin{tabular}{|c|c|c|c|c|c|}
\hline \multirow{3}{*}{$\begin{array}{c}\text { Dates } \\
\text { d'échantillonnage }\end{array}$} & \multicolumn{5}{|c|}{ Ensilage } \\
\hline & \multicolumn{5}{|c|}{ Fourrage de } \\
\hline & Tournesol & Colza & Herbe & Foin & Pâturage \\
\hline Décembre 1969 & 47 & 51 & 50 & 12 & \\
\hline Janvier $1970 \quad \ldots$ & 51 & 60 & 39 & 30 & \\
\hline Février $1970 \ldots \ldots$ & 48 & 40 & 36 & 35 & \\
\hline Mars $1970 \ldots \ldots$ & 51 & 28 & 16 & 39 & \\
\hline Avril $1970 \quad \ldots \ldots$ & 47 & 34 & 40 & 21 & \\
\hline Mai $1970 \ldots \ldots$ & 52 & 24 & 29 & 30 & \\
\hline $1^{\mathrm{er}}$ juin $1970 \ldots$ & & & & & 28 \\
\hline 14 juin $1970 \ldots$ & & & & & 20 \\
\hline 22 juin $1970 \ldots$ & & & & & 18 \\
\hline 21 juillet $1970 \ldots$ & & & & & 20 \\
\hline
\end{tabular}




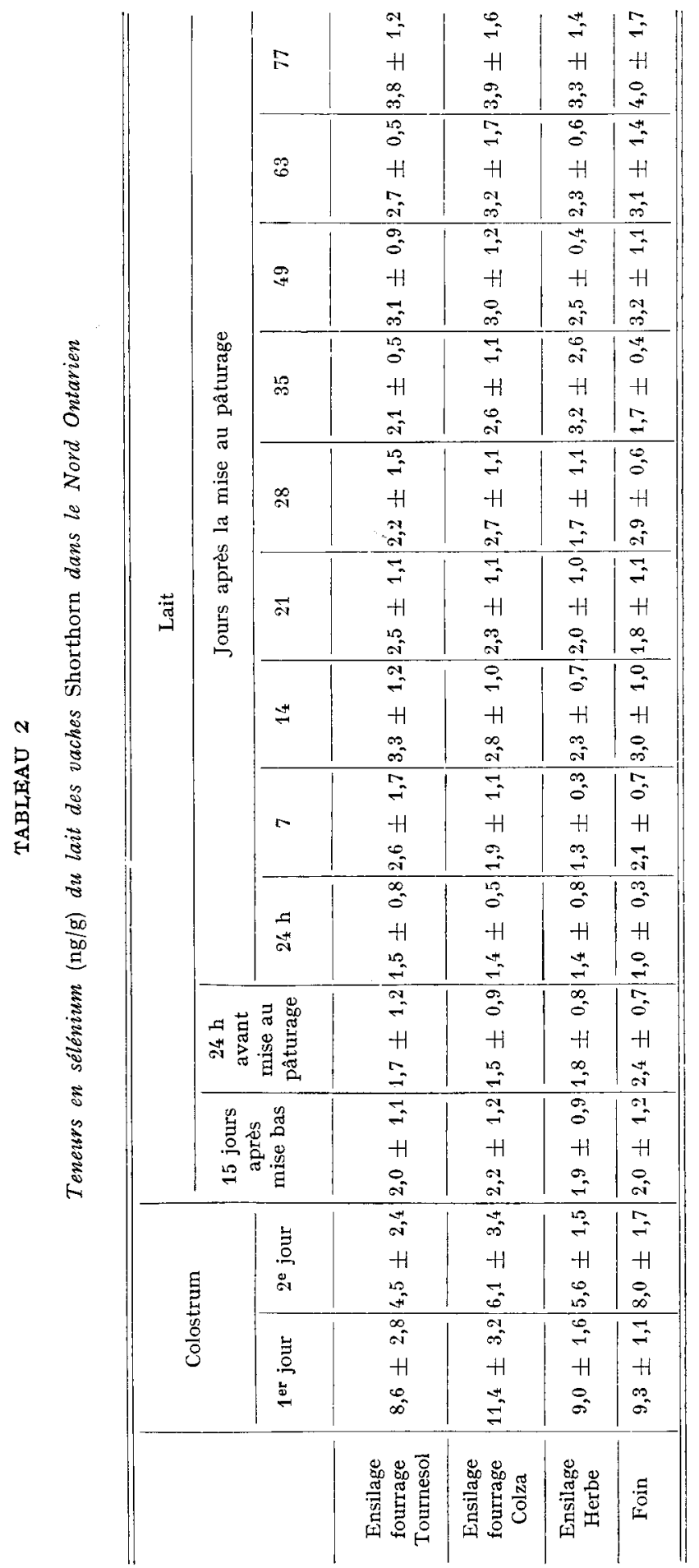


composition en sélénium du lait, lequel était de même ordre de grandeur que le lait des vaches des régions scandinaves (BISBerg et al., I970; JACobsson et al., 1970) ou de l'état de l'Oregon, États-Unis (Hadjimarkos and Shearer, I973) où sévit à l'état endémique la myopathie des veaux. Les teneurs en sélénium des laits ont eu tendance à décroître au fur et à mesure de l'avancement de la saison hivernale, alors que dans la saison pastorale, elles étaient plus élevées à la fin qu'au début de la mise au pâturage.

Si le colostrum de tous nos animaux était riche en sélénium le premier jour, la teneur a diminué après la mise bas et, ${ }_{5}$ jours plus tard, le sélénium du lait représentait seulement un quart de la valeur trouvée dans le colostrum. Il en résulte que, dans le Nord Ontarien, les vaches ne peuvent pas, en allaitant leurs veaux, fournir la quantité de sélénium nécessaire pour éviter l'incidence de la dystrophie musculaire. Dans ce cas, il va de soit qu'une supplémentation en sélénium du composé minéral destiné aux vaches allaitantes est nécessaire, comme l'a proposé Lamand (1972).

Rę̧ pour publication en juillet 1972.

\section{SUMMARY}

\section{SELENIUM LEVEL IN THE MILK OF SHORTHORN COWS}

Changes in selenium concentration in the milk of Shorthorn cows associated with a change from a winter diet either of grass, rapeseed, sunflower silages or hay to lush spring pasture were examined. During the winter feeding period, the selenium levels in the colostrum ( 8.6 to II.4 ng/g) and milk ( $\mathrm{I} .5$ to 2.4 ) were low. There was not a significant change in the milk selenium after the cows were turned out to spring grass which could affect the incidence of nutritional muscular dystrophy of calves.

\section{RÉFÉRENCES BIBLIOGRAPHIQUES}

Bisberg B., Jochemsen P., Rasbech N., I97o. Selenium content in organs, milk and fodder of the cow. Nord. Vet. Med., 22, 532-535.

Hadjimarkos D. M., Shearer T. R., I973. Selenium in mature human milk. Am. J. Clin. Nutr., 26, $583-585$.

Hidiroglou M., Nelson F. C., Lessard J. R., TAylor P. A., I967. Serum transaminase activity in calves affected by nutritional muscular dystrophy in northern Ontario. Can. Vet. Jour., 8, 62-69.

Hoffman I., Westerby R., Hidiroglou M., I968. Precise fluorometric microdetermination in agricultural materials. J.A.O.A.C., 5, 1039-1042.

Jacobsson, Lidman, LindBerg P., r97o. Blood selenium in a beef herd affected with muscular dystrophy. Acta Vet. Scand., 11, 234-326.

Lamand M., r972. Intérêt de la prophylaxie de la myopathie du veat par addition de sélénium aux compléments minéraux des mères. Ann. Zootech., 21, 29-35.

Lessard J. R., Hidiroglou M., Carson R. B., Dermine P., ig68. Intraseasonal variations in the selenium content of various forage crops at Kapuskasing, Ontario. Can. J. Plant Sci., 48, 58I-585. 